\title{
Emotional Maturity among adolescents and its importance
}

\author{
Mridula C. Jobson \\ Clinical Psychologist, MGM Healthcare Private Ltd., Chennai. \\ Corresponding author: Mridula Jobson \\ Email - mridulacjobson@gmail.com
}

\begin{abstract}
Background: Emotional maturity is the ability to understand and manage emotions. Emotional maturity enables adolescent create a fulfilled happy life which helps them to lead a healthy social and individual life. Methodology: The main purpose of the study is to determine the level of emotional maturity among adolescents and factors influencing them. The study was performed with 100 participants, including 53 girls and 47 boys of age group between 17 and 18. Data was collected using the emotional maturity scale by Singh and Bhargava. The collected data was analyzed with statistical package for social sciences (SPSS).

Results: According to results, $74 \%$ of the participants were found to be extremely emotionally Immature. Factors such as age, gender of the participants, type of family and sibling had no association with emotional maturity of the participants.

Conclusion: This study helps to understand the level of emotional maturity among adolescents which creates awareness to provide focus on adolescent with unstable emotional maturity.
\end{abstract}

Keywords: emotional maturity, adolescents, depression, family, self esteem

(Paper received $-9^{\text {th }}$ February 2020, Peer review completed $-26^{\text {th }}$ February 2020)

(Accepted $-26^{\text {th }}$ February 2020)

\section{INTRODUCTION}

Adolescence period is the major part of life where the evolution from the childhood to adulthood occurs. This stage marks the most important changes like biological, cognitive, social and emotions. Emotional maturity refers to the ability to understand, and manage emotions [1]. It helps to create a healthy individual and social life. Emotional maturity can also be defined as, "the capability of adolescents to stabilize emotions which include emotional progression, independence, social adjustment, emotional stability, personality integration, etc". The period between the age group of 10 and 19 are termed as adolescence. Most important development such as physical, mental and social development occurs rapidly during this phase of life. The factors which influence during this age group either create an affect or effect with the individual and last almost entire life [2].

According to World Health Organization the period of adolescence begins with the onset of physiologically normal puberty, and ends when an adult identity and behaviour are accepted. Emotional maturity is considered as one of the major determinants in shaping an individual's personality, behaviour and attitudes and it helps in enhancing the relationship with others and to enhance the self-worth of the person. The survival of the individual in the current situation depends upon how emotionally the situation is being coped up. Hence emotional maturity plays a major role is building the capacity to make effective adjustment with him, family members, his peers, society, culture and his or her environment. The most outstanding mark of emotional maturity is the ability to bear tension and it will enable a person to tolerate the frustration they undergo. An important indication of emotional maturity is that the individual assesses a situation critically before responding to it unthinkingly as like an immature person or a child. This results in adolescents 
ignoring many stimuli that would have caused emotional outburst when they are younger. The more stable an adolescent respond to the situation and the emotional response towards the situation creates emotionally mature adolescents [3-4].

According to Yashvir Singh and Mahesh Bhargava, emotional immaturity includes emotional instability and it is basically individuals lack of capacity in solving problems and they will show case irritability and always wanted help from others they seem to be more stubborn and usually showcase temper tantrums [5]. The second area is all about emotional regression; it includes the characteristics such as feeling of inferiority, restlessness, hostility, self-centeredness, etc. The third area is social adjustment, individuals who have social maladjustment will be having lack of social adaptability and have hatred, they seem to be exclusive but always boasting, they are mostly identified as liars. The fourth area is personality integration, where those who possess personality disintegration will be showing fears, phobias, etc. independence is the fifth area, where those who lack independence, seem to be showing more parasitic dependence, where, they will be overly dependent on others.

Others consider them as unreliable [6]. Recognizing adolescence is important hence it becomes the period of life with specific health and developmental needs and rights. It is also a time to develop knowledge and skills, learn to manage emotions and relationships, and acquire attributes and abilities that will be important for enjoying the adolescent years and assuming adult roles. Age is a convenient way to define adolescence. But it is only one characteristic that delineates this period of development, but in today's situation Age is not the whole story. Age also does not determine the maturity of the individual. All societies recognize that there is a difference between being a child and becoming an adult [7]. This thought creates age is sufficient to determine the capability of the individual but always tend to forget whether the person is emotionally matured to handle the situation.

In many countries, however, this is changing. The Changes are now linked to psychosocial, emotional, cognitive and intellectual changes which were earlier linked only to the hormonal and neurodevelopmental changes. Over the course of the second decade, adolescents develop stronger reasoning skills, logical and moral thinking, and become more capable of abstract thinking and making rational judgments. Changes taking place in the adolescent's environment both affect and are affected by the internal changes of adolescence. Humans rely heavily on learning for development. Because humans are not born knowing how to behave in society, learning many of the behaviours occurs from the environment around us growing up. Learning starts with the family at home. It comes in many forms. Sometimes learning occurs directly by self. But the most common way humans learn is by observation of everyday life. Especially during adolescence most of the learning occurs from environment. The fore most becomes the Family. The role of family in influencing an adolescent way of living and growing into adult is primary and prominent and unavoidable [8].

The family acts as a foundation if it is not strong, the adolescent will have trouble standing on own. Adolescent might find it more difficult to be successful in relationships with others, work, health and within. Importance of family influence in development of a human is inevitable. Emotional maturity is of great significance in today's competitive world where every individual learns to develop stability intra- personally and inter-personally. It is found out that less emotionally mature persons tend to prefer inefficient coping methods than that of useful methods and the more mature people prefer more wise and useful methods [9]. At present adolescence period is more prone to press to stress. They undergo huge level of stress and conflicts during this period, if an adolescent is emotionally mature, he or she can deal with the stress very effectively. This study focused to find out the level of emotional maturity among adolescents and to establish if any, correlation exists between the family and emotional maturity. This study will be a basement for the further studies in the area.

\section{METHODOLOGY}

\section{Research Design}

The Correlation with in group research design is used to find the relationship between type of family, age, gender and emotional maturity of adolescents. Self-report questionnaires were administered to the participants for data collection and quantitative approach was used to test the proposed hypotheses. 


\section{Objectives of the study}

1. To assess the level of emotional maturity among adolescents and compare the areas of emotional maturity

2. To assess between family type and emotional maturity among adolescents

3. To assess between sibling and emotional maturity among adolescents

4. To assess between age variables and emotional maturity among adolescents

5. To assess between gender and emotional maturity among adolescents

\section{Sample}

The samples were selected from various higher secondary schools and College from southern district in Tamil Nadu. Sample selected was between the age group of 16-18 years. Selective Sampling method was used to identify 100 adolescent students and only students got the consent from their parents was participated in the study.

\section{Inclusion of Criteria}

1. Adolescent willing to participate.

2. Adolescents pursuing higher secondary education and Under-graduation

3. Adolescent between age of 16 and 18 years

4. Adolescents only from southern parts of Tamil Nadu.

\section{Exclusion of Criteria}

1. Adolescents belonging to age below 15 and above 19 .

2. Adolescents who are mentally challenged.

3. Adolescents from other geographical areas.

\section{Instrument for Data collection}

Socio-demographic questionnaire was used to collect basic demographic details. It is a form designed to obtain some important information about the participants and to obtain the necessary information in order to be included in the research groups.

Emotional maturity scale developed by Singh and Bhargava [10] was used to collect the data. The scale consists of 48 items which are classified into five broad categories of emotional maturity.

1. Emotional stability- 10 items

2. Emotional progression- 10 items

3. Social adjustment- 10 items

4. Personality integration- 10 items

5. Independence- 8 items

It is a self-reporting five-point scale with the scoring of much -5 , much -4 , undecided -3 , probably -2 , never 1 . Higher the score on the scale, greater the degree of emotional immaturity. The test-retest reliability has been estimated at 0.75 and validity against the Adjustment Inventory by Singh and Bhargava (1980) at 0.46 , and the interpretation of the scores: 50-80 extremely stable; 81-88 moderately stable; 89-106 unstable; 107- 240 extremely unstable. The students filled the questionnaires within 20-30 minutes and all the scoring sheets were collected for further data analysis. The raw score obtained was analysed using SPSS.

\section{RESULTS}

Table 1:Frequency and percentage table of Socio-demographic variables

\begin{tabular}{|l|l|l|}
\hline Demographic Variables & Frequency & Percentage \\
\hline Gender & 47 & $47 \%$ \\
\hline Male & 53 & $53 \%$ \\
\hline Female & 53 \\
\hline Age & 55 & $55 \%$ \\
\hline 17 years & 45 & $45 \%$ \\
\hline 18years & & \\
\hline
\end{tabular}




\begin{tabular}{|c|c|c|}
\hline \multicolumn{3}{|l|}{ Type of family } \\
\hline Nuclear family & 72 & $72 \%$ \\
\hline Joint family & 28 & $28 \%$ \\
\hline \multicolumn{3}{|l|}{ Siblings } \\
\hline No & 8 & $8 \%$ \\
\hline Yes & 92 & $92 \%$ \\
\hline \multicolumn{3}{|c|}{ Current studying institution } \\
\hline Government aided & 50 & $50 \%$ \\
\hline Private college & 50 & $50 \%$ \\
\hline \multicolumn{3}{|c|}{ Residential background } \\
\hline Urban & 50 & $50 \%$ \\
\hline Rural & 50 & $50 \%$ \\
\hline \multicolumn{3}{|c|}{ Economic background } \\
\hline Low & 61 & $61 \%$ \\
\hline Middle & 29 & $29 \%$ \\
\hline High & 10 & $10 \%$ \\
\hline
\end{tabular}

The above table 1 shows the demographic profile of the participants. More than half of the proportion of the participants were female (53\%) and the remaining $47 \%$ were male. Most of the participants were in the age of 17 years (55\%) and (45\%) of the participants were 18 years. Nearly 3/4th proportion of the participants $(72 \%)$ lives in nuclear family and $28 \%$ live in joint family. Most of the participants $(92 \%)$ have siblings and the remaining (8\%) doesn't have siblings. Half of the participants $(50 \%)$ were studying in government aided school and the remaining $(50 \%)$ study in private college. $50 \%$ of the participants were from urban background and remaining (50\%) were from rural background. Majority of participants (61\%) were from economically lower background and 29\% participants were from middle class and followed by remaining $(10 \%)$ were from higher economic background.

Table 2: Total distributions of emotional maturity levels of the participants

\begin{tabular}{|l|l|l|}
\hline Variable & Frequency & Percentage \\
\hline Moderately Emotional Mature & 10 & $10 \%$ \\
\hline Emotional Immature & 16 & $16 \%$ \\
\hline Extremely Emotional Immature & 74 & $74 \%$ \\
\hline Total & 100 & $100 \%$ \\
\hline
\end{tabular}

The above table (Table 2) shows distribution of emotional maturity level of the participants analyzed using the emotional maturity scale. Most (74\%) of them were extremely emotional immature and $16 \%$ of them were emotional immature and $10 \%$ of the participants were moderate emotional mature.

Table 3: Means of total sample on emotional maturity and its dimensions

\begin{tabular}{|l|l|}
\hline Emotional Maturity- Category & Mean Value \\
\hline Emotional stability & 26.35 \\
\hline Emotional progression & 27.68 \\
\hline Social Adjustment & 27.44 \\
\hline Personality integration & 25.95 \\
\hline Independents & 20.94 \\
\hline
\end{tabular}


The above table (Table 3) Reveals the mean of total sample on emotional maturity and its dimension among participants. The category emotional progression was relatively higher than other dimensions of emotional maturity with a mean value of 27.68. Followed by the category Social Adjustment with the mean value of 27.44. The participants expressed emotional stability with mean value of 26.35 , Personality integration with mean of 25.95 . Finally respondent has Independents emotional maturity with mean value is 20.94

Table 4: Associations between family type and emotional maturity

\begin{tabular}{|l|l|l|l|l|l|}
\hline Family Type & $\begin{array}{l}\text { Moderate } \\
\text { Emotional } \\
\text { Mature }\end{array}$ & $\begin{array}{l}\text { Emotional } \\
\text { Immature }\end{array}$ & $\begin{array}{l}\text { Extremely } \\
\text { Emotional } \\
\text { Immature }\end{array}$ & Total & p value \\
\hline Nuclear Family & $10(10 \%)$ & $13(13 \%)$ & $49(49 \%)$ & $72(72 \%)$ & $\begin{array}{l}\mathrm{X}^{2}=5.796 \mathrm{a} \\
\mathrm{df}=2 \\
\mathrm{p}=0.55\end{array}$ \\
\hline Joint Family & Nil & $3(3 \%)$ & $25(25 \%)$ & $28(28 \%)$ & $100(100 \%)$ \\
\hline
\end{tabular}

The above table (Table 4) reveals the association between the type of family and Emotional Maturity. Majority (72\%) of the participants were found Nuclear family and followed by (28\%) of them were Joint family. There is no significant association between family type and emotional maturity. Since $\mathrm{P}>0.05$ the results were not statistically significant.

Table 5: Associations between sibling and emotional maturity

\begin{tabular}{|l|l|l|l|l|l|}
\hline Sibling & $\begin{array}{l}\text { Moderate } \\
\text { Emotional } \\
\text { Mature }\end{array}$ & $\begin{array}{l}\text { Emotional } \\
\text { Immature }\end{array}$ & $\begin{array}{l}\text { Extremely } \\
\text { Emotional } \\
\text { Immature }\end{array}$ & Total & p value \\
\hline Yes & 9 & 14 & 69 & 92 & $\begin{array}{l}\mathrm{X}^{2}=0.650 \\
\mathrm{df}=2\end{array}$ \\
\hline No & 1 & 2 & 5 & 8 & $\mathrm{p}=0.723$ \\
\hline Total & 10 & 16 & 74 & 100 & \\
\hline
\end{tabular}

The above table (Table 5) revealed association between sibling variables and emotional maturity. Most (92\%) of the participants have siblings and $8 \%$ of the participants do not have sibling. (69\%) of adolescents with siblings were found to be extremely emotional immature. $\mathrm{P}$ value $>0.05$ the results are not statistically significant hence there exist no association between siblings and emotional maturity levels of the participants.

Table 6: Associations between age and emotional maturity

\begin{tabular}{|l|l|l|l|l|l|}
\hline Age & $\begin{array}{l}\text { Moderately } \\
\text { Emotional mature }\end{array}$ & $\begin{array}{l}\text { Emotional } \\
\text { Immature }\end{array}$ & $\begin{array}{l}\text { Extremely } \\
\text { Emotional } \\
\text { Immature }\end{array}$ & Total & p value \\
\hline 17 years & $5(5 \%)$ & $4(4 \%)$ & $46(46 \%)$ & $55(55 \%)$ & $\begin{array}{l}\mathrm{X}^{2}=7.453 \\
\mathrm{df}=2\end{array}$ \\
\cline { 1 - 5 } 18years & $5(5 \%)$ & $12(12 \%)$ & $28(28 \%)$ & $45(45 \%)$ & 0.24 \\
\hline Total & $10(10 \%)$ & $16(16 \%)$ & $74(74 \%)$ & $100(100 \%)$ & $\mathrm{p}=0.24$ \\
\hline
\end{tabular}

The above table (Table 6) revealed that association between age variables and emotional maturity. There exist no association between age and emotional maturity. 18 years old adolescents were found to be less extremely immature than 17 years adolescent. Since $\mathrm{P}>0.05$ the results are not statistically significant Table 7 shows the association between gender variables and emotional maturity. There is no association between gender and emotional maturity. Females were found to be slightly extremely emotional immature when compared with males, Since $p>0.05$ the results are not statistically significant. 
Table: 7 Associations between gender and emotional maturity

\begin{tabular}{|l|l|l|l|l|l|}
\hline Gender & $\begin{array}{l}\text { Moderate } \\
\text { Emotionally } \\
\text { Mature }\end{array}$ & $\begin{array}{l}\text { Emotional } \\
\text { Immature }\end{array}$ & $\begin{array}{l}\text { Extremely } \\
\text { Emotional } \\
\text { Immature }\end{array}$ & Total & p value \\
\hline Male & $3(3 \%)$ & $9(9 \%)$ & $35(35 \%)$ & $47(47 \%)$ & $\begin{array}{l}\mathrm{X}^{2}=1.712 \\
\mathrm{df}=2\end{array}$ \\
\cline { 1 - 4 } $\mathrm{pemale}$ & $7(7 \%)$ & $7(7 \%)$ & $39(39 \%)$ & $53(53 \%)$ & 0.425 \\
\hline Total & $10(10 \%)$ & $16(16 \%)$ & $74(74 \%)$ & $100(100 \%)$ & $\mathrm{p}$ \\
\hline
\end{tabular}

\section{DISCUSSION}

The results present the outcomes of the data analysed to explore the research questions of the present investigation. Adolescence marks the important phase of human life span. The major learning process takes place during this phase. All the adolescents will grow up in to a person who pre-occupies different professions and sometimes most of them may turn into powerful authorities. Hence emotional maturity plays a vital role on how the individual grows. Without emotional maturity, it is difficult to succeed in their life goals. To lead a healthy social and individual life, adolescent should need to be emotionally matured. Emotional maturity helps the adolescent to lead a socially appropriate way of life and it helps them to guide themselves on what to do and what not do. Family influence forms the basis of learning. This study focuses to assess the level of emotional maturity among adolescents and to find whether type of family, siblings, age and gender of the participants influences emotional maturity among adolescents.

The previous studies conducted on last five years stated that the students having both parents, single parent or without parent, living in joint family or nuclear family, single child of their parents or having few siblings, enjoying a high status or lower status of family, residing in urban or rural area; factors found to produce an effects their level of emotional maturity.

The results of the present study showed that only $16 \%$ were emotionally matured whereas $16 \%$ were emotionally immature and 74\% extremely emotional immature thus the outcome reveals that more than 70 $\%$ of adolescents who were involved in this study was found to be emotionally immature. The results also state that no association was found to be significant. Positive environmental factors may lead to high level of emotional maturity among students while negative settings of environment may lead to low level of emotional maturity among students. In case of the present study the reason may be the shift of the term environment in case of adolescence age group. The environment- An adolescent spends more time is found to be with his or her peer group environment rather than the family environment. Hence this study projection of no association of family or sibling makes us think beyond the primary environment family to the peer group influenced environment. The positive the peer group environment the more emotionally matured the adolescent becomes [11]

The study also witnessed no association between the age, gender and emotional maturity similar to the study conducted by Bhattacharya [12]. It stated no significant association between gender and emotional maturity. Even though 18 years old adolescents were found to be matured than 17 years old, the results were not statistically significant. Adolescent turmoil persists today, much of the current research on adolescent development within families fails to support the view that parent- adolescent relationships chronically involve severe conflict and dramatic growth in emotional distance. For most youth, the family remains the primary arena of social influence and security, both for fostering positive and negative consequences. Although a significant minority of adolescents certainly do experience a persistent pattern of troubled family relationships [13], for the majority, a more balanced and positive view prevails about the influence of home life in adolescent development. Sometimes positivism from family when expected from society is not delivered shall make the adolescent more vulnerable to face society and alters the esteem hence making them emotionally immature, dependent and in-stable.

From the perspective of the social sciences, Socialization is a complex, multi-directional process involving the family, as perhaps the most important source of influence, but also involving all the major institutions and social settings in which individuals (i.e., adolescents) have direct or indirect experiences (e.g., religious 
institutions, work settings, schools, the mass media, political and governmental institutions, as well as neighbourhoods and communities).

\section{CONCLUSIONS}

A pattern of dynamic interaction exists between developing adolescents and their social environments, which includes influential factors from different levels of ecological analysis at the biological, physical, psychological, and sociocultural levels. Hence type of family and sibling cannot stand alone as the major influence of the adolescent emotional maturity. This study acts as an indicator to understand that the environment either primary family or peer group, the environment decides the emotional maturity in case of adolescent. Hence creating the best environment helps the child to grow into the emotionally matured adult. The role of the parent or guardian to be aware of the environment the adolescent is growing and altering the negative consequences into positive environment creates a huge impact.

\section{Recommendations for future studies}

1. It can be conducted on a more appropriate sample size

2. Probability sampling can be used

3. The geographical area of selecting sample should not be restricted to one place; the further researchers can focus on much more geographical areas to get a valid data.

4. Comparative study can be conducted between boys and girls or Nuclear family and joint family.

\section{REFERENCES}

1. Heaven PC. The social psychology of adolescence. Palgrave Macmillan; 2001.

2. Simmons RG, editor. Moving into adolescence: The impact of pubertal change and school context. Routledge; 2017.

3. Rawat C, Gulati R. Influence of Home Environment and Peers Influence on Emotional Maturity of Adolescents. Integr J Soc Sci 2019;6(1):15-8.

4. Rajan CS, Joseph HB. Self esteem and emotional maturity among adolescents. Int J Nurs Care 2019;7(1):279.

5. Goswami M, Roy P. Emotional maturity of higher secondary students in relation to some selected variables. Int J Res Soc Sci 2019;8(2):456-67.

6. Rawat C, Singh R. The Paradox of Gender Difference on Emotional Maturity of Adolescents. J Hum Ecol 2017;58(3):126-31.

7. Duhan K, Punia A, Jeet P. Emotional Maturity of Adolescents in Relation to their Gender. Int J Educ Sci Res (IJESR) 2017;7(1):61-8.

8. Aggarwal P. A study of stress among adolescent students in relation to their emotional maturity and family climate. Int J Res Soc Sci 2018;8(4):106-17.

9. Rawat C, Singh R. A study of emotional maturity of adolescents with respect to their educational settings. J Soc Sci 2016;49(3-2):345-51.

10. Singh Y, Bhargava M. Emotional maturity scale. Tehran: Allameh Tabatabaei University Publication. 1999.

11. Bhattacharjee A. Emotional maturity among young adults: A comparative study. Indian J Psychol Sci 2016;6(2):73-9.

12. Bhattacharya P. Prediction of Perception of Home environment of Indian Adolescents basic of their Emotional Intelligence. Int J Indian Psychol 2015;2(3):20-4.

13. Arnett JJ. Learning to stand alone: The contemporary American transition to adulthood in cultural and historical context. Hum Dev 1998;41(5-6):295-315.

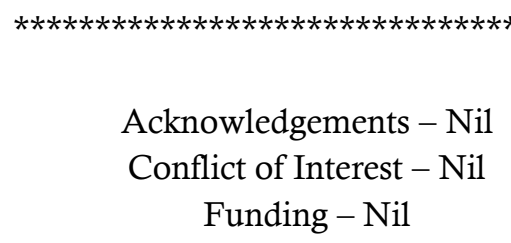

Indian Journal of Mental Health 2020;7(1) 